\title{
Wideband Antenna for 4G MIMO
}

\section{Applications}

Caitlin Kenny ${ }^{1}$, Johann W. Odendaal ${ }^{1}$, Johan Joubert ${ }^{1}$

${ }^{1}$ Centre for Electromagnetism, University of Pretoria, Pretoria 0002, South Africa; Corresponding author: caitlin.kenny@za.saabgroup.com

ABSTRACT - A small, wideband, multiple-input-multiple-output (MIMO) antenna is presented for 4G Long Term Evolution (LTE) applications. The proposed antenna consists of a vertically polarized wideband stepped slot, as well as a horizontally polarized narrowband, uniform slot, integrated on a single substrate and fed by two ports. A prototype of the proposed antenna was designed, fabricated and measured. The stepped slot antenna achieves an enhanced bandwidth of $122 \%$ from $0.77 \mathrm{GHz}$ to $3.12 \mathrm{GHz}$, covering the $2 \mathrm{G}, 3 \mathrm{G}$ and $4 \mathrm{G}$ bands. The narrowband slot achieves a bandwidth of $35 \%$ from $2.11 \mathrm{GHz}$ to $3.01 \mathrm{GHz}$, covering the $4 \mathrm{G}$ band frequencies only. The isolation between the two slots is greater than $21 \mathrm{~dB}$ over the entire band of interest. The radiation pattern of the wideband slot in the horizontal plane is omnidirectional in nature while the narrowband slot exhibits a bi-directional radiation pattern in the horizontal plane. The proposed antenna is suitable for indoor, ceiling-mount, micro-cell 4G LTE applications.

Keywords: 4G, LTE, MIMO, wideband 


\section{INTRODUCTION}

The fourth generation $(4 \mathrm{G})$ of mobile technology has faster data rates than the preceding third generation (3G) technology. Data rates of $100 \mathrm{Mb} / \mathrm{s}$ can be expected for high mobility users whilst low mobility users will experience data rates up to $1 \mathrm{~Gb} / \mathrm{s}$ [1]. It is speculated that approximately $70 \%$ of the demand for high speed data services originates from indoor environments [2]. Although the latest $4 \mathrm{G}$ technology has been released, $2 \mathrm{G}$ and $3 \mathrm{G}$ technology is still widely in use and the availability of a single wideband antenna suitable for all the frequency bands; $2 \mathrm{G}, 3 \mathrm{G}$ and $4 \mathrm{G}$ (with multiple-input multiple-output (MIMO) capabilities in the $4 \mathrm{G}$ band) would be highly advantageous.

A number of antennas for $4 \mathrm{G}$ applications are available. These antennas comply with the requirements for the $4 \mathrm{G}$ frequency band with MIMO capabilities but are not operational in the $2 \mathrm{G}$ and $3 \mathrm{G}$ frequencies bands [3], [4]. Wideband antennas which achieve the bandwidth requirements (2G, 3G and 4G) are not suitable for 4G applications due to their lack of MIMO capabilities [5], [6]. Wideband MIMO antennas [2] suitable for $2 \mathrm{G}, 3 \mathrm{G}$ and $4 \mathrm{G}$ applications tend to be large with complex manufacturing processes and some exhibit non-ideal radiation patterns [7].

In this paper a compact indoor ceiling mount antenna covering the $2 \mathrm{G}, 3 \mathrm{G}$ and $4 \mathrm{G}$ bands, with $\mathrm{MIMO}$ capability for the $4 \mathrm{G}$ band is presented. The design entails a simple and low cost fabrication procedure. The proposed antenna will find application in indoor, ceiling-mounted micro-cells. The novelty of the design presented is seen in the wideband operation of the antenna, with MIMO capabilities in the $4 \mathrm{G}$ band, in conjunction with its advantageous radiation patterns for indoor application and simple manufacturing process. 


\section{ANTENNA GEOMETRY AND DESIGN}

The geometry of the proposed antenna is shown in Fig. 1. The antenna comprises of a wideband stepped slot, and a narrow band uniform slot. The wideband slot is functional over a wide band covering the $2 \mathrm{G}, 3 \mathrm{G}$ and $4 \mathrm{G}$ bands while the second slot covers only the $4 \mathrm{G}$ band. The wideband slot is vertically polarized whilst the narrowband slot is horizontally polarized. The opposing polarizations ensure maximum isolation between the two slots.

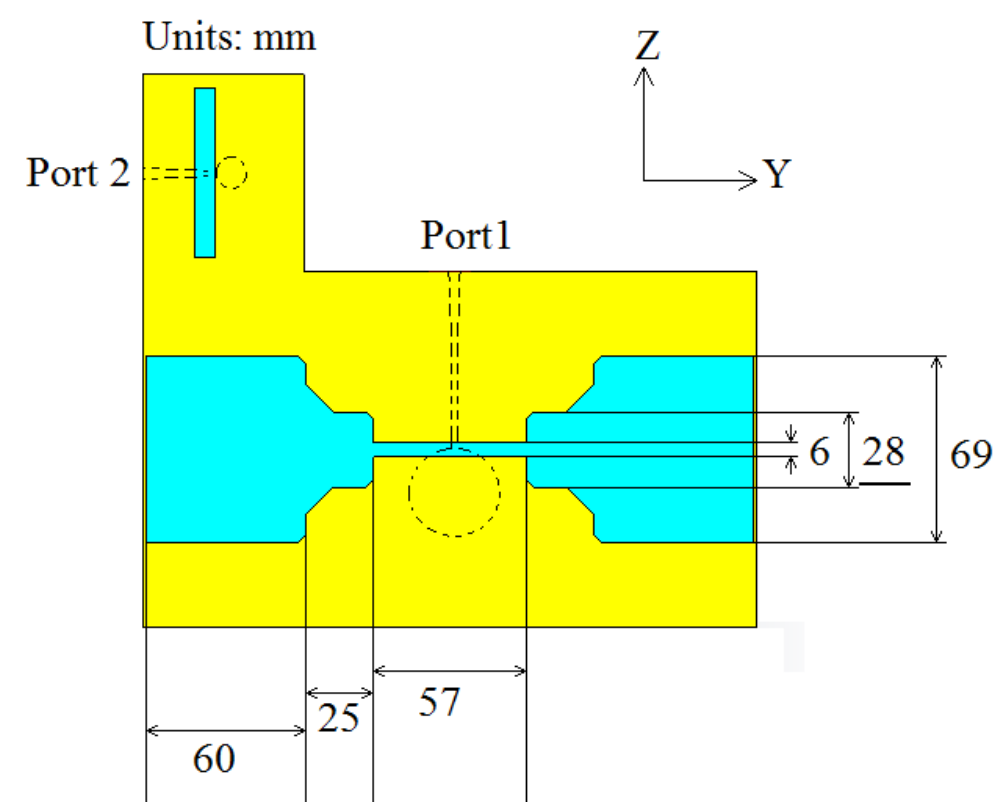

Fig. 1. Schematic of optimized antenna geometry.

\section{A) Wideband Antenna}

In order to achieve a sufficiently wide bandwidth, a stepped slot antenna was implemented. As can be seen from Fig. 1, a total of three steps were introduced into the wideband slot. Each step is responsible for introducing a resonance in its corresponding band, viz. $790 \mathrm{MHz}$ to $960 \mathrm{MHz} ; 1700 \mathrm{MHz}$ to $2200 \mathrm{MHz}$ and $2300 \mathrm{MHz}$ to $2700 \mathrm{MHz}$. These steps drastically improve the impedance bandwidth of the design. The introduction of a 45 degree chamfer between selected steps improved the radiation patterns of the design whilst maintaining a good reflection coefficient over the entire band. A circular stub microstrip-to-slotline transition was implemented to feed the slot. 


\section{B) Narrowband Antenna}

The second slot antenna was designed to be operational from $2.3 \mathrm{GHz}$ to $2.7 \mathrm{GHz}$ such that it would be functional for 4G MIMO applications. The slot is approximately half a wavelength at the centre frequency of the band. A circular stub microstrip-to-slotline transition was implemented as feed for the uniform slot.

\section{EXPERIMENTAL VALIDATION}

A prototype antenna was measured in a compact range as illustrated in Fig. 2. The simulated and measured reflection coefficients of slot 1 and slot 2 are presented in Fig. 3. A strong correlation between simulated and measured results is observed. The reflection coefficient remains below $-10 \mathrm{~dB}$ from $0.77 \mathrm{GHz}$ to $3.12 \mathrm{GHz}$ for the wideband slot and $2.11 \mathrm{GHz}$ to $3.01 \mathrm{GHz}$ for the narrow band slot. An isolation of $21 \mathrm{~dB}$ or more was maintained from $0.5 \mathrm{GHz}$ to $4 \mathrm{GHz}$ between the two ports.

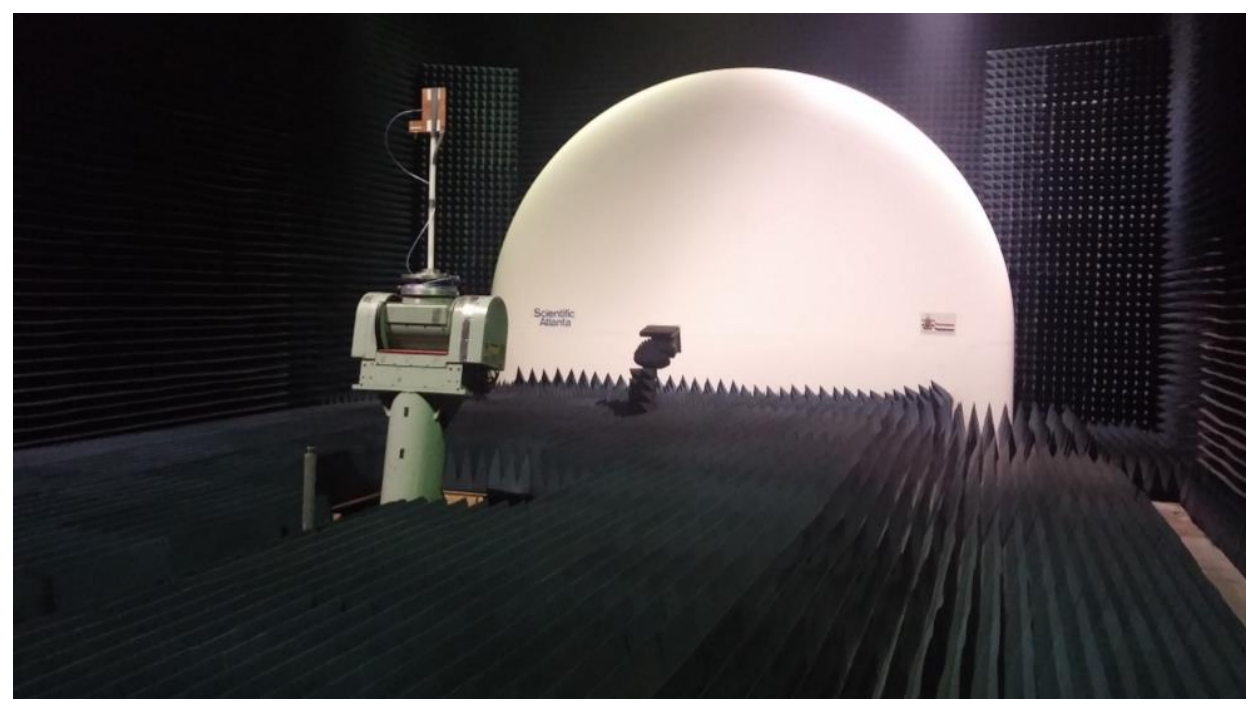

Fig. 2. Antenna measured in compact range.

The simulated and measured radiation patterns in the horizontal (XY-plane) at $900 \mathrm{MHz}, 2 \mathrm{GHz}$ and 2.5 GHz are shown for the wideband slot in Fig. 4, Fig. 5 and Fig. 6, respectively. The radiation pattern of the narrow band slot at $2.5 \mathrm{GHz}$ in the horizontal plane is presented in Fig. 7. Once again a 
strong correlation between simulated and measured data exists. The patterns of the wideband antenna all appear to be omnidirectional in nature while the narrow band antenna displays patterns which are bi-directional.

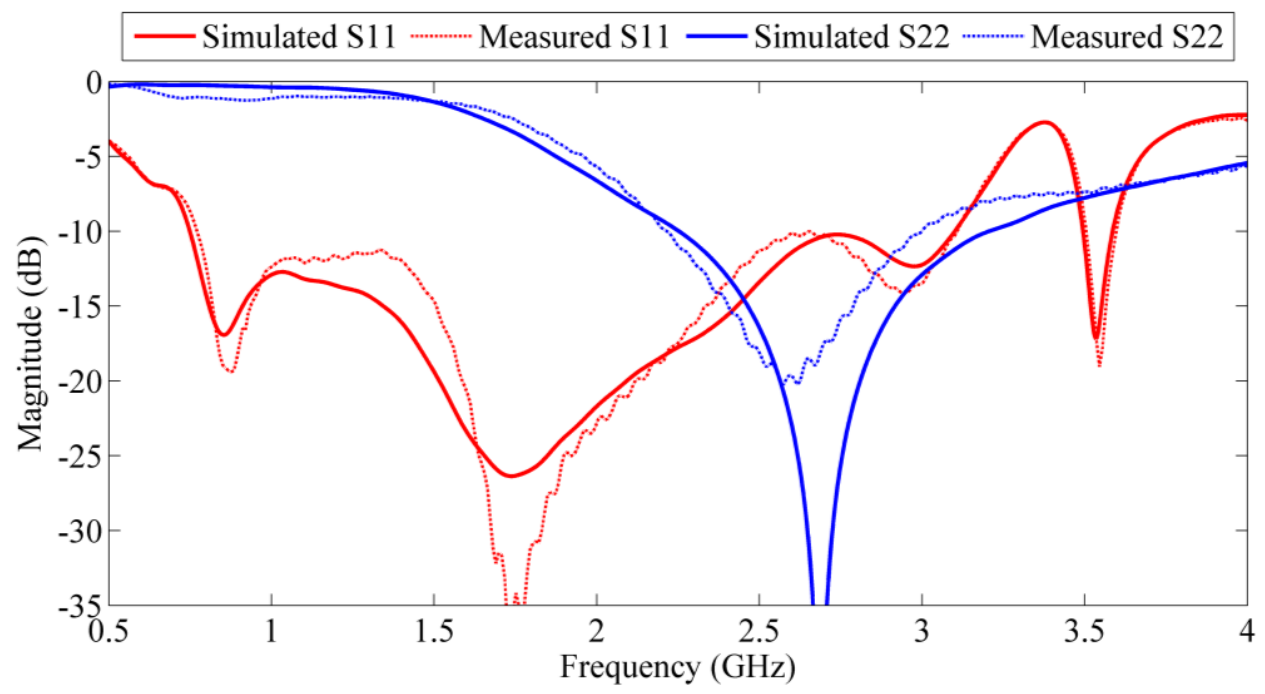

Fig. 3. Measured and simulated reflection coefficients for the wideband slot (S11) and the narrowband slot (S22)

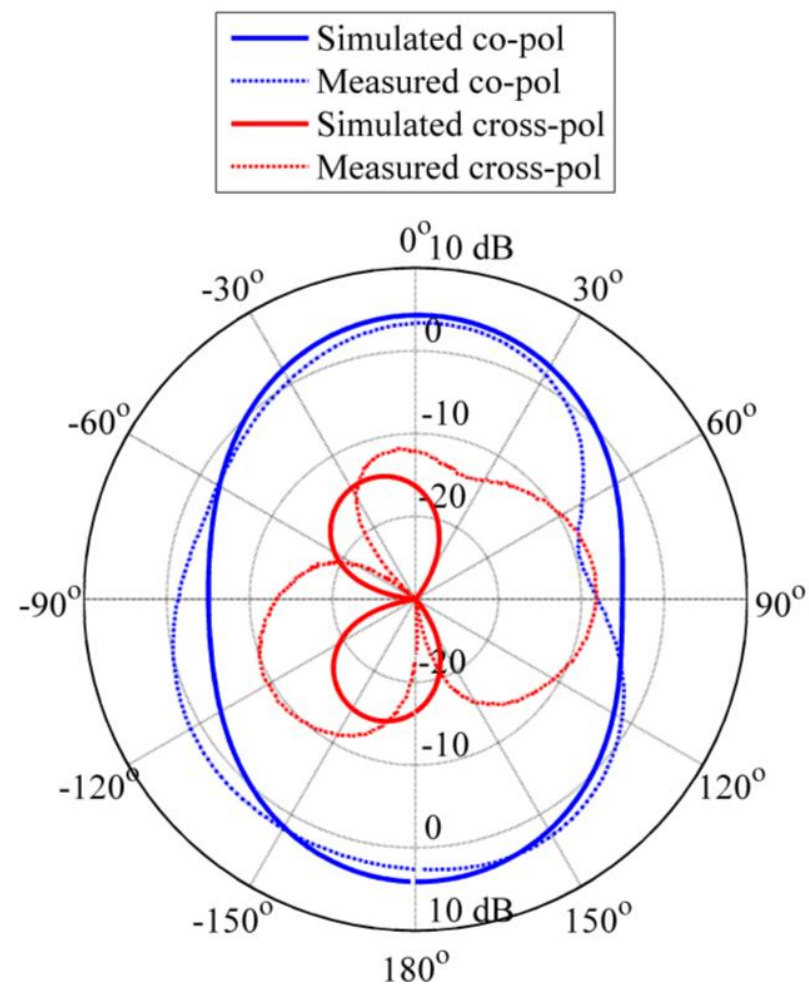

Fig. 4. Wideband slot radiation pattern in the horizontal plane at $0.9 \mathrm{GHz}$. 


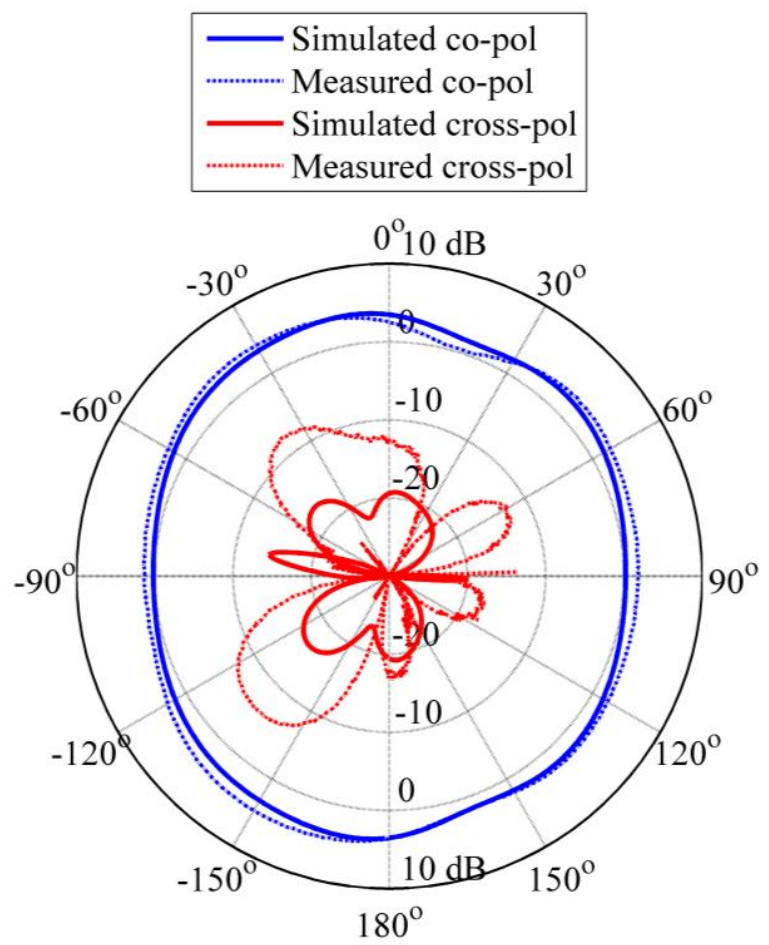

Fig. 5. Wideband slot radiation pattern in the horizontal plane $2.0 \mathrm{GHz}$.

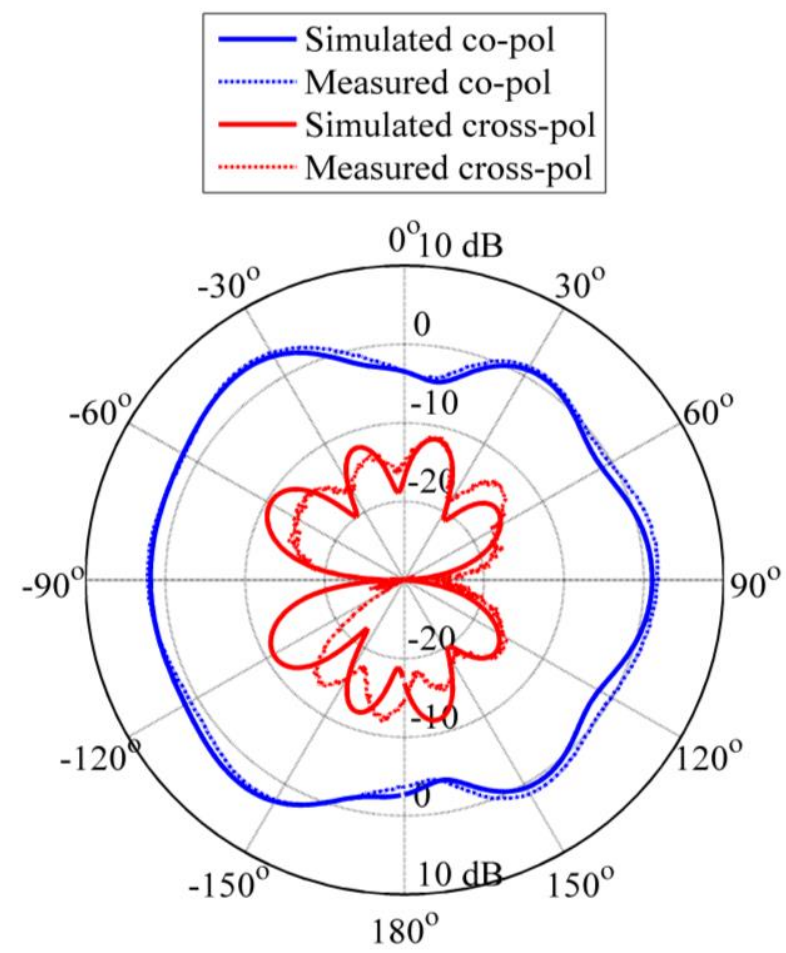

Fig. 6. Wideband slot radiation pattern in the horizontal plane at $2.5 \mathrm{GHz}$. 


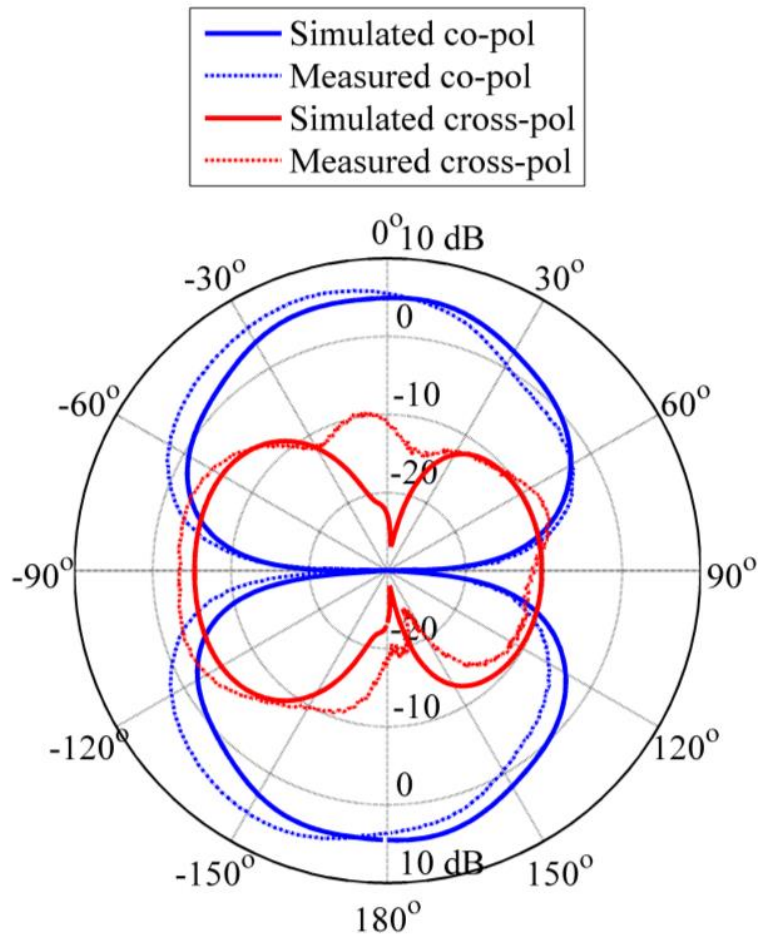

Fig. 7. Narrowband slot radiation pattern in the horizontal plane at $2.5 \mathrm{GHz}$.

The gain of the wideband slot and the narrowband slot are illustrated in Fig. 8 and Fig. 9, respectively. The maximum gain was measured in the horizontal plane. The wideband slot exhibits an average gain of $3.7 \mathrm{dBi}$ over the operational band whilst the narrowband exhibits an average gain of $5.1 \mathrm{dBi}$ over its operational band. The wideband slot exhibits a theoretical radiation efficiency of $81.5 \%$ or better from $0.75 \mathrm{GHz}$ to $3 \mathrm{GHz}$. The uniform slot exhibits a theoretical radiation efficiency of $91.6 \%$ or better from $2.11 \mathrm{GHz}$ to $3 \mathrm{GHz}$. 


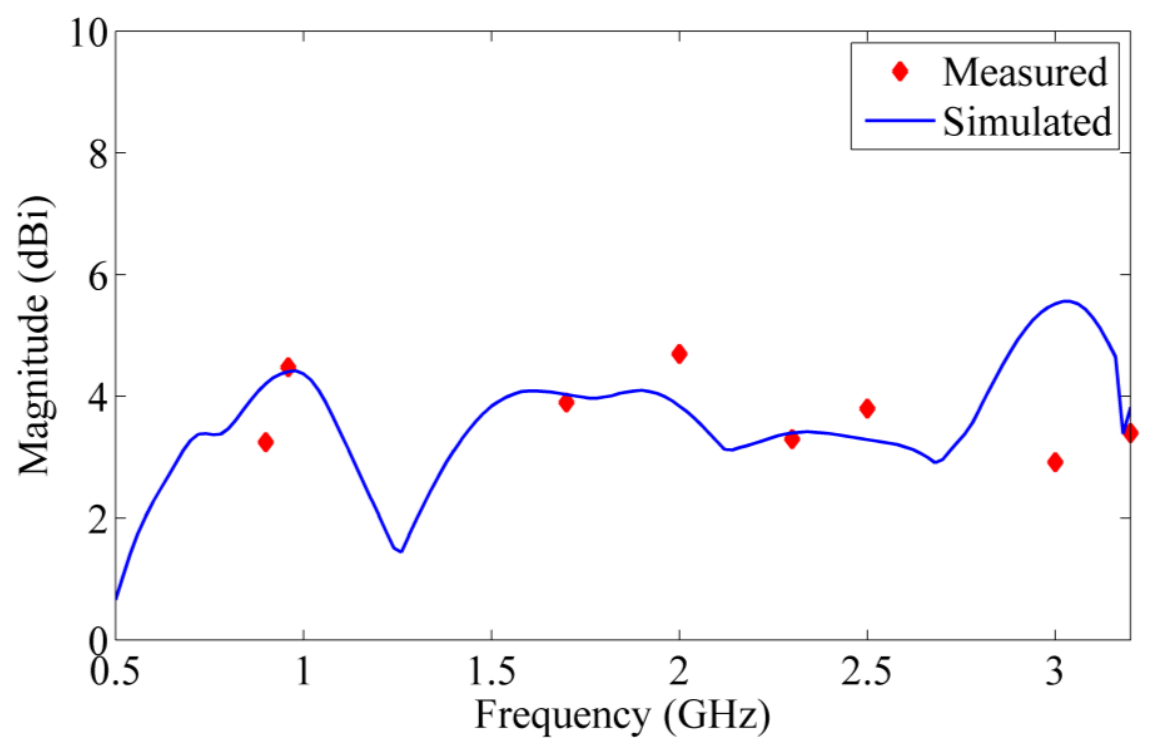

Fig. 8. Measured and simulated gain of the wideband slot.

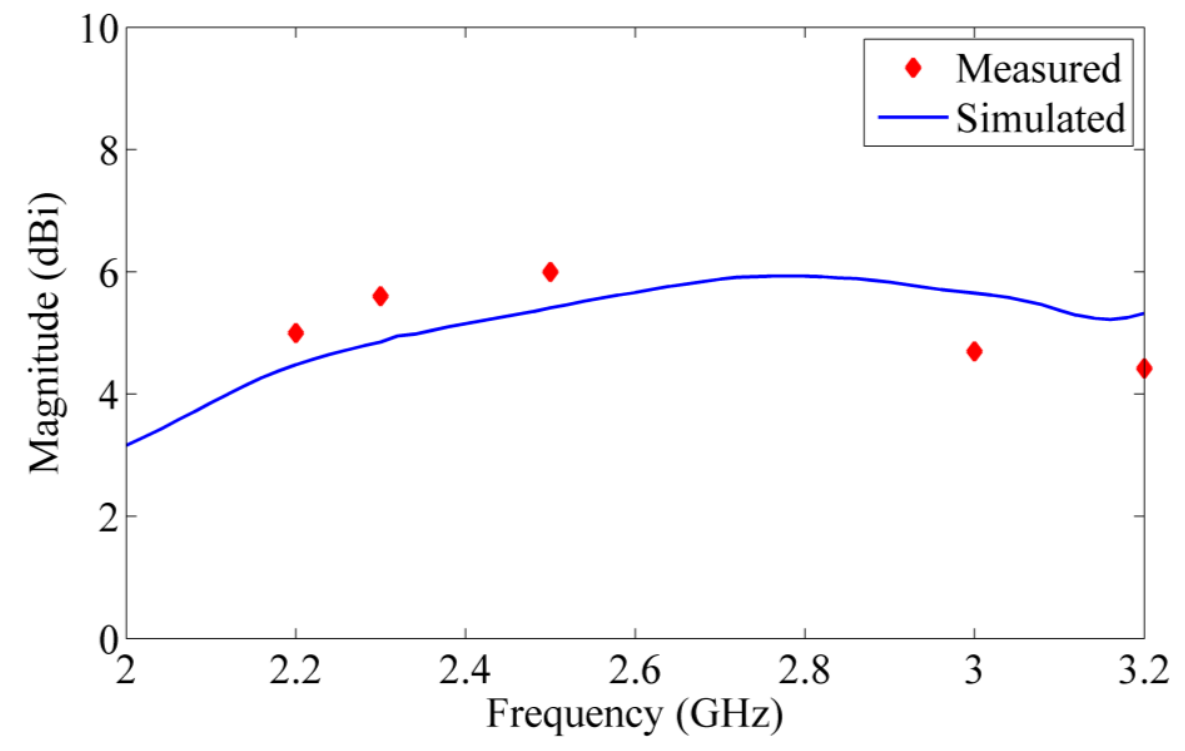

Fig. 9. Measured and simulated gain of the narrowband slot.

\section{CONCLUSION}

A novel wideband, vertically polarized antenna with MIMO capabilities has been presented for indoor, ceiling-mounted applications. It covers the GSM 900 and GSM 1800 bands of 2G, the UMTS 900 and 
UMTS 1800 bands of 3G and the LTE 2600 band of 4G. Measured and simulated results show good correlation. The antenna meets the wideband and MIMO requirements whilst maintaining a relatively simple fabrication process.

An enhanced bandwidth of $121 \%$, from $0.77 \mathrm{GHz}$ to $3.12 \mathrm{GHz}$, is achieved by means of implementing a stepped slot antenna configuration with chamfered corners. The stepped slot is fed by a microstripto-slotline transition. A second slot radiator, also fed by a microstrip-to-slotline transition, with an operational bandwidth of $35 \%$ from $2.11 \mathrm{GHz}$ to $3.01 \mathrm{GHz}$ allows for the antenna to be MIMO in the 4G band. The wideband slot antenna is vertically polarized and has a relatively omnidirectional radiation pattern in the horizontal plane. The second slot antenna is horizontally polarized and has a bidirectional pattern in the horizontal plane. Measured and simulated results show good correlation.

\section{REFERENCES}

1. Y.Y. Yu, F. Jolani, and Z. Chen, A wideband omnidirectional horizontally polarized antenna for 4G LTE applications, IEEE Antennas and Wireless Propag Lett 12 (2013), 686-689.

2. L. Sun, W. Huang. B. Sin. Q. Sun, and J. Fan, Two-port pattern diversity antenna for 3G and 4G MIMO indoor applications, IEEE Antennas Wireless Propag Lett 13 (2014), 1573-1576.

3. F. Ahmed, Y. Feng, and R. Li, Dual wide-band four-unit MIMO antenna system for 4G/LTE and WLAN mobile phone applications, In : Loughborough Antennas and Propag Conf, Loughborough, UK, 2013, pp. 202-207.

4. A.N. Kulkami and, S.K. Sharma, A Compact Multiband Antenna with MIMO Implementation for USB Size 4G LTE Wireless Devices, In: IEEE International Symp on Antennas and Propag, Spokane, USA, 2011, pp. 2215-2218. 
5. L. Zhou, Y.-C. Jiao, Y. Qi, Z. Weng, and T. Ni, Wideband ceiling mount omnidirectional antenna for indoor distributed antenna system applications, Electron. Lett 50 (2014), 253-255.

6. N.I.M. Elamin, T.A. Rahman, and A.Y. Abdulrahman, New Adjustable Slot Meander Patch Antenna for 4G Handheld Devices, IEEE Antennas and Wireless Propag Lett 12 (2013), 10771080.

7. E. Yetisir, C.-C. Chen, and J. L. Volakis, "Low-profile UWB 2-port antenna with high isolation, IEEE Antennas and Wireless Propag Let 13 (2009), 55-58. 